\title{
Global Competence in Higher Mining Engineering Education
}

\author{
Inna Pevneva ${ }^{1, *}$, Paul Edmunds ${ }^{2}$, and Anna Smirnova ${ }^{3}$ \\ ${ }^{1}$ Kemerovo institute (branch) of Plekhanov Russian University of Economics, Department of \\ Humanities, 650992 Kuznetsky pr.39, Kemerovo, Russia \\ ${ }^{2}$ University of New Mexico, Center of English Language and Culture, 871012111 Mesa Vista Hall, \\ Albuquerque, Albuquerque, USA \\ ${ }^{3}$ Kemerovo State University, Department of Germanic and Romance studies, 650000 Krasnaya ul., 6, \\ Kemerovo, Russia
}

\begin{abstract}
The formation of global competences for learners at all levels of professional engineering and mining education as the basis for the successful career and social life has become increasingly urgent in modern fast-changing world. The solution to this problem involves several aspects: first, identification and description of the basic elements and the structure of the global competences within the competency-based approach; second, the interpretation of global competences and their components taking into account convergent and divergent global processes in all spheres of human activity. Third, the development of tools to facilitate the reform of education, to ensure the quality improvement of the educational process, procedures, evaluation of results and ensuring the growth of quality indicators of the results of education.
\end{abstract}

\section{Introduction}

Modern society as never before is exposed to new global trends and constant economic, cultural, technological and environmental changes that are part of the globalization process. Increasing global interdependence requires a generation of professionals who will be able to participate in the tackling of global problems and be active in the society contributing to sustainable development. So far, we've met the term "global competence" in Russian education in connection with the participation in the PISA project (Program for International Student Assessment), which monitors the quality of high school students general education. Thus, global competence is undoubtedly the innovative determinant and an integrative element of higher engineering education.

Global competence within the PISA assessment project is understood as "the ability to critically examine different perspectives and problems of a global nature of intercultural interaction; understand how cultural, religious, political, racial or other differences can affect perception, judgment and views of people; engage in an open, respectful and effective interaction with others on the basis of shared respect» [1]. However, the

\footnotetext{
* Corresponding author: Inna_nag@mail.ru
} 
emergence of global competences (GC) does not stop with the school graduation. Vocational education at any level is the main source of learning about the world for a new generation of learners [1].

It is worth noting that the competence approach in education was formed as a response to globalization, amplified by the total computerization and internet access, as a reaction to the growing global and in-country changes in a wide variety of areas, including in the labour market. Therefore, the system of professional education is to prepare its graduates to any possible change by developing skills such as mobility and dynamism as they determine the competitiveness of graduates in the labour market.

Dr. Jürgen Kohler emphasizes that competences involve features that are available not only due to the amount of knowledge gained, but more of how this knowledge can be used, i.e. in mindfulness, rationality of action. Such multidimensional interpretation of competencies allows to consider them from the point of view of the generic competences beyond the specific professions and majors. The development and implementation of teaching methods of Global competences in its aspect of diagnostics is described by Beetham H., McGill L., Littlejohn A., Binkley M., Erstad O., Herman J., Raizen S., Ripley $[2]$.

\section{Methods}

The subject of this research is the global competence in education process of engineering students and students of economic and technical universities. The goal primarily is to describe the basic elements and the structure of Global competence as well as a synthesis of it.

The major stages of the study assumed the following tasks:

1. Description of the external prerequisites of development of Global competences.

2. Analysis of the existing definitions in methodological literature and periodicals.

3. Identification of the key elements and structure.

4. Assessment of the level of Global competence formation for students.

5. Consider examples of integration in higher professional education in the United States.

Today students must be able to freely navigate in a multilanguage environment with the intercultural competence being formed through integration into the global educational process tasks on development of critical thinking skills, intercultural communication skills, tolerance and respect to the realities of other cultures. All teaching materials should be based on contemporary issues and events of everyday life. In the process of language acquisition, students analyze the similarities and differences between the realities of his native country and the country of the language leant. The teacher's role is to help students assimilate information, to express their attitude to the world, events, set out ways of avoiding errors and conflicts in interpersonal and group interactions. Using games, trainings, project activities, interactive methods and problem-based learning, communicative method is an effective way of building a multicultural global competence.

\section{Results}

1. Globalization, the digital revolution, mass migration and the prospect of an unstable climate give rise to new challenges and require new types of university graduates. Indeed, a growing number of reports of international organizations reflect new requirements and opportunities for young people. They are calling for more effective, relevant, and independent learning, which will prepare young people for life, competition and cooperation under the new global scenario. The result of normal relationships is the process 
of globalization of unprecedented scale, breathtaking speed and consequences. Furthermore, employers are increasingly looking for competent, reliable people who will work at an affordable cost, regardless of the location of the employee and the workplace. Thus, a completely new process of labour division is emerging.

Note that the list of the most professions in demand projected to 2025 includes such jobs that did not exist ten years ago (for example, in the sphere of technology and telemedicine, social intelligence and new media etc.). It is in these areas as futurologists and experts say global competition will prevail.

2. Many researchers agree that a key component of global competences is an effective intercultural communication and foreign language skills. However, there is no consensus on the question of the level of foreign language knowledge, which is necessary for the student of economics or technical specialty in order to achieve the level of global competence [3-4]. Hunter and his colleagues describe the specialist that has a well-developed global competence as "...broad-minded individual who seeks to understand the cultural norms and expectations of others and able to use the acquired knowledge for successful interaction, communication and effective work out of a familiar environment". Darla Deardorff presents several definitions of global competence, two of which include linguistic competence and foreign language skills. Based on these definitions the concept of cross-cultural competence and the competence of foreign language are both the key components of global competences [5]. Within this research we will stick to the definition adopted by the Committee of the Asian Centre for Global education and the Organization for economic cooperation and development: "Global competence is the capacity and disposition to understand and act on issues of global significance "[1].

3. There is no stated set of the basic skills necessary for the formation of Global competence so far. It ranges from self-learning, thinking and innovative skills to skills related to lives and careers such as creative and systemic thinking to skills to design, evaluate and manage one's own work for continuous improvement and adaptation to change. Nevertheless, they all involve dynamic orientation training. Analysis of the literature and observations with data and recommendations of the Asia Society Centre for global education and the Organization for Economic Cooperation and Development (OECD) Global competences irrespectively of the area, include four required elements: investigating the world, recognizing perspectives, communicating ideas and taking action.

To be competitive, ethical and effective employees, graduate students need to understand key topics of global importance in areas such as engineering, business, science, history, ecology and other areas where they can work. They should learn to think and work as experts, to understand the economic, technological and social forces that shape their lives and future work. There is a global growing percentage of new immigrants who unlike previous generations of migrants and due to the digital revolution will maintain in close contacts with their countries and participate in the religious, economic, cultural and political processes. Many countries support initiatives aimed at deepening international understanding in school and university curricula. For example, in the Maastricht declaration on global education, representatives of the European Council put forward a framework for global education, calling to "open eyes and minds to the realities of the world and arouse them to create more justice and equality of human rights for all "[6].

4. To assess the level of Global competence formation for students of economic and engineering majors, we have conducted a survey with the request to self-assess their global competence skill at the present moment ranking from 0 (not formed) to 5 (formed very well) thus presenting the average results. We intentionally do not make any statistic verification as the goal was simply to see the overall picture. We have conducted survey on global competence formation of students both male and female in 2018 (86 students in total aged 18-25) in the universities of Kuzbass region. 
Table 1. The assessment of Global Competence formation of students.

\begin{tabular}{|c|c|c|c|c|}
\hline $\begin{array}{c}\text { Key } \\
\text { elements of } \\
\text { GC }\end{array}$ & $\begin{array}{l}\text { Investigate the } \\
\text { world }\end{array}$ & $\begin{array}{c}\text { Recognize } \\
\text { perspectives }\end{array}$ & $\underset{\text { ideas }}{\text { Communicate }}$ & Take action \\
\hline $\begin{array}{c}\text { Global } \\
\text { Competence } \\
\text { skills of the } \\
\text { basic level }\end{array}$ & $\begin{array}{l}\text { Use knowledge } \\
\text { of language and } \\
\text { culture to } \\
\text { identify issues } \\
\text { and frame } \\
\text { researchable } \\
\text { questions }\end{array}$ & $\begin{array}{l}\text { Recognize and } \\
\text { express their own } \\
\text { perspectives and } \\
\text { understanding of } \\
\text { the world and } \\
\text { determine how } \\
\text { culture shape } \\
\text { those } \\
\text { perspectives }\end{array}$ & $\begin{array}{l}\text { Recognize and } \\
\text { express how } \\
\text { linguistically } \\
\text { diverse people may } \\
\text { perceive different } \\
\text { meanings form the } \\
\text { same words and } \\
\text { how this impacts } \\
\text { communication }\end{array}$ & $\begin{array}{c}\text { Use native } \\
\text { and studied } \\
\text { language and } \\
\text { culture to } \\
\text { identify and } \\
\text { create } \\
\text { opportunities } \\
\text { for personal } \\
\text { or } \\
\text { collaborative } \\
\text { action to } \\
\text { improve } \\
\text { conditions }\end{array}$ \\
\hline $\begin{array}{c}\text { Students of } \\
\text { foundation } \\
\text { course/intern } \\
\text { ational } \\
\text { students }\end{array}$ & 3 & 3 & 2 & 2 \\
\hline $\begin{array}{l}\text { Freshmen } \\
\text { (1st course) }\end{array}$ & 1 & 1 & 2 & 2 \\
\hline $\begin{array}{l}\text { Graduates } \\
\text { (4th course) }\end{array}$ & 3 & 2 & 4 & 2 \\
\hline
\end{tabular}

The results show that international students in general feel themselves rather confident in investigating the world and recognizing perspectives and less confident in communicating ideas and taking action. They feel they are more able to recognize and express their perspectives and see how linguistic diversity influences perception. Freshmen students feel themselves less equipped with this knowledge and skill, mostly due to the lack of international exposition at their local schools. Graduate student, having spent four years in an international university environment feel themselves more confident in these skills, especially in understanding the culturally justified specifics of perception. However, they still lack the active and most important skill of taking an action and identifying opportunities. Integration of Global competence tasks into curriculum may contribute to improvement of this situation.

5. The following elements are advised to integrate into the academic teaching that can contribute to the development of global competence.

Involving students to solve global problems. Digital natives have motivation to study only if they see and understand its relevance to their individual lives and major global challenges that create new opportunities for improving living conditions. Key concepts of social observation, such as migration and urbanization can be explored on a global scale, art provides virtually unlimited opportunities for organized study of global problems and finding creative responses. As these examples show, the global learning competence involves finding new meaningful ways to rethink the information that teachers often present avoiding frivolous or superficial relationships.

Globalization of education. Consideration of any academic course content from a global perspective provides opportunities for in-depth understanding and perfection of critical 
thinking skills. Classes of foreign language offers unlimited possibilities in terms of integration the tasks on global competencies in the form of analysis of world literature, mass-media resources, case reviews. For example, students may examine international efforts to mitigate climate change by conducting policy analysis particularly through the study of original documents of the countries (in a national language). This analysis could be enhanced by careful study of public opinion on environmental policies of countries drawn from newspapers and other sources [7].

International Mobility projects. Undoubtedly, students with intercultural exchange experience gain global competence faster and easier than those who have no opportunity to immerse themselves in the culture of another country. Video conferencing, social networking and other communication technologies now provide students with opportunities to explore issues of global importance with other students around the world [8-10]. There are many ways to structure such interaction between student ranging COIL classes to joint artistic undertakings. Opportunities to learn through virtual channels are also widely available to students through universities, scientific organizations, non-profit organizations and enterprises.

In the United States there exists a variety of university settings which approach the concept of GC from very little to highly active. Demonstrations of embracing GC can be disseminated through classroom instruction related to international topics, internationalization at home through the blending of domestic with international students, and via mobility programs as described earlier. At the University of New Mexico (UNM), all three of these modalities exist and are exercised to differing extents. Teacher training around the phenomenon of $\mathrm{GC}$ is addressed in different ways. For example, for regular academic faculty members, the Center for Teaching and Learning offers seminars and workshops for faculty with topics related to GC. In particular, seminars have been given to address common questions such as how to work with international students in the classroom in general, international students from a variety of cultures simultaneously, as well as with speakers of English as a second or other language.

At the intensive language program Center for English Language and American Culture (CELAC) at UNM, new ESL teachers are given training on working with students from different language and cultural backgrounds upon initial employment, and ongoing professional development training sessions occur throughout each semester, many of which address concepts of GC such as understanding cultural differences, understanding how language is manifested in part by cultural differences, and how language learners need a specific support system that often touches on the concept of GC.

Although we have not yet specifically surveyed students in the CELAC program, anecdotal evidence would suggest that our students become stronger in terms of GC during their duration of study, typically between 2 months and 1.5 years in the English language center. Students with lower linguistic abilities will have more difficulty understanding or describing abstract concepts, so recognizing perspectives may be more challenging, as will be communicating abstract ideas. As language skills increase, the ability to communicate both concrete and abstract concepts increases, and students' ability to investigate the world and take action on ideas becomes greater. As CELAC often enrolls students from over 20 countries simultaneously, future research will involve investigating differences both at a linguistic level and by way of cultural background.

An element of feedback that is continuously present from our intensive language programming is the ability of students to transition smoothly into regular academic, degreeseeking studies at the university upon completion of the English program. We have tracked the academic success of both undergraduate and graduate students and have found that both groups perform with grade point averages (GPA) of 3.5 or better on a 4.0 scale across all disciplines. Student feedback has demonstrated their ability to enter courses such as College 
Composition very well, competing and very often prevailing academically over their domestic, native-English speaking peers. This success is not only attributed to their linguistic abilities in the English language but also most certainly to their high functioning GC. The students have been immersed in an international setting, have learned the tools to comprehend and perceive elements of topics related to GC or domestic issues in general, and continue to fine-tune their skills to successfully complete programming in a global context. This success promotes the further teaching and analysis of GC and urges for more research, analysis, and conversation to be carried out on this increasingly important topic as international students complete their studies in the United States, take their GC with them to their home or other countries, and share their background in GC with domestic and international colleagues alike.

\section{Discussion}

The world to which universities should prepare young people is qualitatively different from the industrial world where the public school system was created. In recent decades numerous reports and policy statements emphasized the need to acquire new skills in the twenty-first century. These global competence frameworks respond to the demands of a changing world differently but recognizing the central role of global interdependence to play in the lives of our young people.

Globally competent graduates are knowledgeable, curious and interested to explore the world. They can operate different ideas, tools, methods and languages to solve the problems of modern society. They develop themselves and apply the experience gained by examining different points of view, exchanging views and taking steps to improve conditions in their society and in the global arena, contributing to future sustainable development. Building global competencies, therefore, is a necessary element of training in professional education, enabling graduates to work effectively and find themselves professionally in an increasingly complex, diverse and interdependent world.

\section{References}

1. The Organization for Economic Cooperation and Development Report (OECD, Washington, 2018)

2. H. Beetham, L. McGill, A. Littlejohn, Thriving in the 21st century: Learning literacies for the digital age (LliDA Project, Glasgow, 2010)

3. E. Care, H. Kim, Let's aspire, but be realistic: What skills can be taught for the 21st century? (Brookings Institution, New York, 2017)

4. A.D. Chan, J. Fishbein, The Journal of Policy Engagement, 1:2, 4-8 (2009)

5. D.K. Deardorff, Journal of Studies in International Education, 3, 241-266 (2006)

6. Maastricht Global Education Declaration (MFED, Maastricht, 2010)

7. F. Reimers, Prospects, 36:3, 275-294 (2006)

8. S.J. Freidheim, Valuing study abroad: The global mandate for higher education (British Academy, London, 2012)

9. A. Mazumder, Making of a Global Engineer: Culture and Technology (ACE, Austin, 2009)

10. J.H. Coatsworth, Globalization, growth, and welfare in history (University of California Press, Berkeley, 2004) 